\title{
What Drives the Viewership of an Online Video-lecture Course? A Case Study
}

\author{
João Alberto Arantes do Amaral**
}

Federal University of São Paulo jarantes@alum.mit.edu

Aurélio Hess

Oswaldo Cruz University hessaurelio@gmail.com

\begin{abstract}
In this article, we discuss the dynamics that led to viewing of 18 five-minute videos, created as part of a business dynamics course and made freely available on Internet. Over a period of five years, the videos were watched 2,740 times in 80 countries. The goal of our research was to understand what dynamics drove the viewership. We collected quantitative data from eighteen Google Analytics reports and from professor's courses log, and made a systems analysis of it. We reached the following conclusions:1) The professor's actions to promote the course enabled direct access on the part of the students; it also led to wider viewership as a result of being picked up by search engines that made the videos available to a wider audience. 2) Once the videos were posted on Youtube, Youtube and search engine algorithms stimulated increased viewership.3) Internet users' actions such as sharing the videos on social networks and embedding the videos on personal websites also stimulated the the number of views.
\end{abstract}

Key words: Systems analysis, videos' viewership, self-study course, video-lectures, searchengines dynamics

* If the article has been presented at any seminar or conference, the name of the conference, the institution where it has been presented and the date of the presentation needs to be mentioned.

** Corresponding author. 


\section{Introduction}

In October 2012, the first author was invited to teach a five-hour lecture on business dynamics in Sao Paulo, Brazil. Students were part of an international Master of Science Program in Business Management. This course was a result of a partnership between the Mauá Institute of Technology of Brazil and Steinbeis University in Germany.

The students were all Germans: they took the majority of the master's course modules in Germany. One of the modules was taught in Brazil by Brazilian professors of the Mauá Institute of Technology. The module was designed to provide the students with an international experience, exposing them to Brazilian business environment and culture.

The business dynamics lecture was part of the module taught in Brazil. The lecture aimed to present the students the main concepts of system dynamics and give them practical examples of application of these concepts in business. Before the lecture, the professor (the first author) created a booklet of exercises to be used during the lecture, along with a companion webpage.

The lecture was given in English to 30 students during the course of one afternoon. At the beginning of the lecture each student received a kit with the booklet and pens. During the lecture, the professor followed a problem-based learning approach. For each concept presented in class, he challenged the students to perform small exercises (sometimes individually, sometimes in groups), solving problems proposed in the booklet. The lecture was intense and demanding: the students were exposed to a variety of concepts in a short period of time.

After the lecture, the professor posted 18 short videos that summarized the key concepts taught in the course on the course's companion webpage (Figure 1). He titled these the System Dynamics Self-Study Course. (thereafter SDSSC). The webpage was made freely available on the Internet; anyone could reach it using searching engines. Each video was approximately five minutes long. The videos were also posted on a Youtube educational video channel created by the professor. 


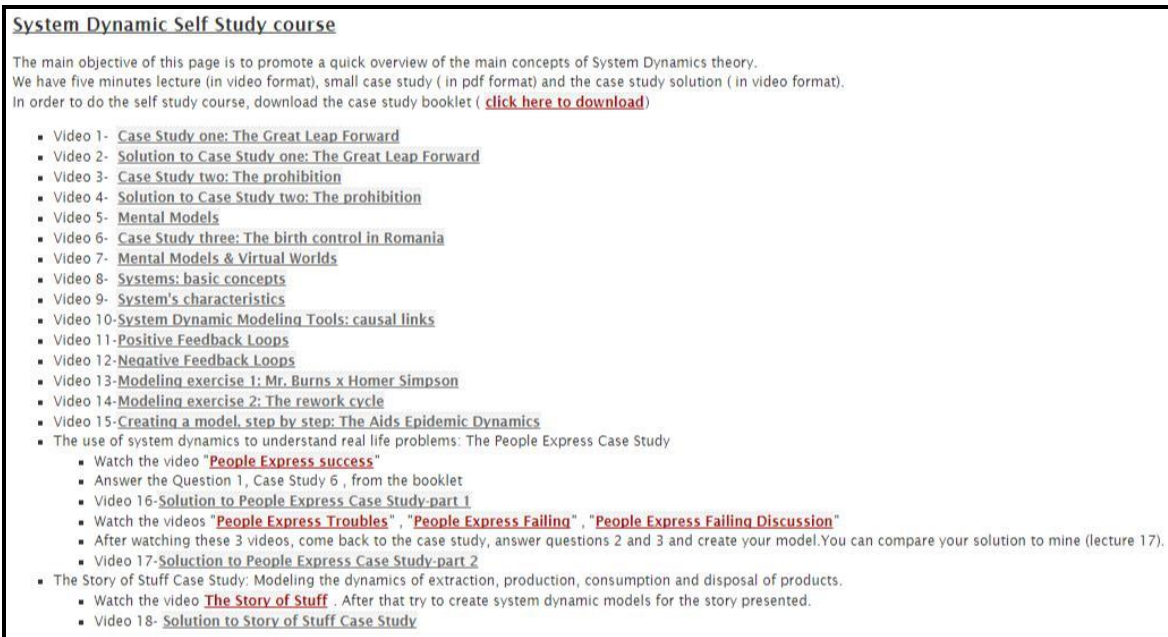

Figure 1. The course webpage

The professor subsequently created a link to the videos (SDSSC) from his own website and from a System Thinking website he created for another course. Over the years, he encouraged his students to visit the link to the webpage in order to review basic concepts of system dynamics..

Five years after the creation of SDSSC, the professor became curious as to whether students had accessed the webpage or not. To find out, he made use of the Google Analytics tool. He was thus able to retrieve information regarding the number of times of each video had been watched, the places from where the users had accessed the video, the origins of Internet traffic to the videos, and many other characteristics (Figure 2). 


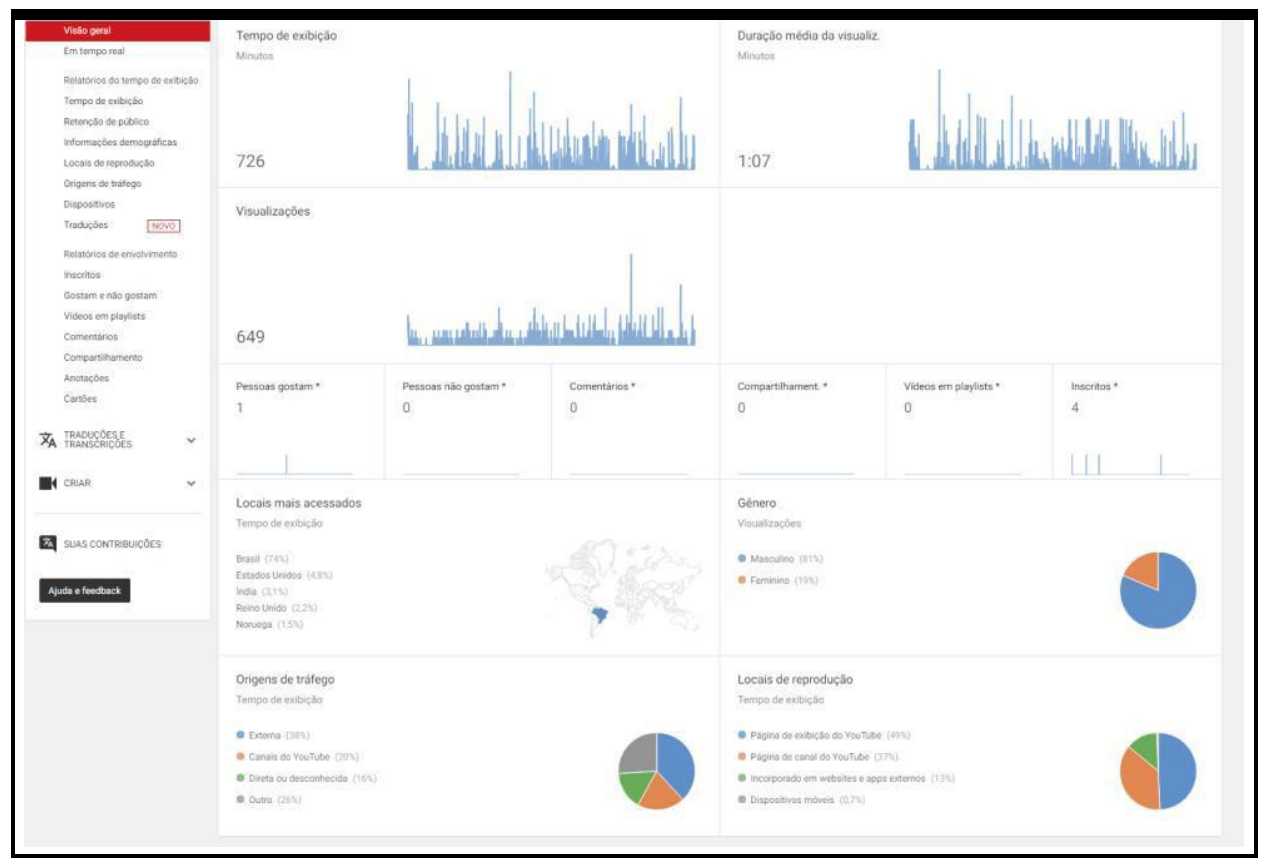

Figure 2. One example of the Google Analytics report interface

He discovered that the videos had been watched by a surprising number of people from countries from all over the world. The research question then became: what were the dynamics that led to the videos being watched? In this article, we share our findings.

\section{Theoretical Review}

Making course material freely available online is not a new idea. The Massachusetts Institute of Technology began to make course content available in 2001, through its OpenCourseWare (OCS) initiative (Abelson, 2008). The movement that began with MIT now aggregates several universities in the OCW Consortium (Lerman \& Potts, 2006). Universities are making their courses' contents available to people worldwide, bringing positive educational impacts (Caswell et all., 2008).

On the other hand, there are individuals, not necessarily scholars, who create video-lectures about subjects of interest and make them freely available to all that may be interested in watching. Online video lectures can be very attractive, since they help the students to learn at their own pace (Brecht, 2012; Simpson, 2006). The students can watch the videos whenever they have time to; they can review difficult topics several times; and they can skip the segments of the videos they consider boring. 
One famous example of an individual who has shared videos on internet is Samuel Khan, who began creating videos to teach his cousins and was surprised by the by the enormous amount of people who watched them (Noer, 2012). Such success brought him proposals by sponsors for financial support, which in turn motivated him to create Khan Academy (Thompson, 2011).

Once the videos are created and made available on video-sharing websites, they can be accessed by people from all over the world. Sites such as Youtube, for example, made it possible for millions of people to download and share videos hosted there (Burgess \& Green, 2013). Youtube has algorithms that help the user to find other videos whose content is closely related to those watched (Davidson et al., 2010). Nowadays, the people share Youtube's videos on their social networking websites such as Facebook and others (Rotman $\&$ Preece, 2010). This increases viewership.

Although there are articles that analyze the characteristics of video sharing (Baluja et al., 2008), there is a lack of information about the dynamics that drive the viewing. This article aims to contribute to fulfillment of this gap.

\section{Method}

In our study, we followed a quantitative research approach, performing a systems analysis of the data obtained. We collected quantitative data from two complementary sources. The first source was from Google Analytics reports. We also collected quantitative data related to the professor's actions to promote the videos, collected from professor's courses log. We then used a system dynamics modeling tool, the causal loop diagram, to represent the dynamics that we believe were responsible for the high number of views.

\section{Findings}

Table 1 presents the number of business dynamics courses taught by the professor from $05 / 10 / 12$ to $07 / 03 / 17$. We collected this data because we wanted to estimate how many students received the information about the SDSSC videos directly from the professor.

Table 1

Number of courses related to System Dynamics taught in Brazilian Universities

$\begin{array}{ll}\text { Institution } & \text { Number of courses taught } \\ \text { University of Sao Paulo } & 6 \\ \text { Mauá Institute of Technology } & 4 \\ \text { University Center UNIFIEO } & 3 \\ \text { Foundation Institute of Administration } & 3\end{array}$


Federal University of Sao Paulo

Total of courses taught

Estimated number of students influenced by the

professor (Number of courses taught $x 20$ )

Table 2 presents the number of websites and Youtube channels created by the professor with links to the SDSSC webpage.

Table 2

Websites and Youtube channels created and maintained by the professor

Websites and Youtube Channels created by the professor and

Professor personal website

System thinking website

Professor's Youtube Channel
Number of links to SDSSC webpage

18 (one link from each video)

Table 3 presents data collected from Google Analytics reports related to the viewing of each video, showing how long each video was watched on average, the number of times of each video was watched and the number of countries in which each video was watched. It also highlights the three countries in which the videos were most watched.

Table 3

Data collected from Google Analytics Reports, from 05/10/2012 to 07/03/2017

$\begin{array}{lllll}\text { Video } & \begin{array}{l}\text { How long } \\ \text { each ve number Number } \\ \text { video of times of of } \\ \text { wamber watched } \\ \text { on average }\end{array} & \begin{array}{l}\text { Top } 3 \text { countries } \\ \text { was watched }\end{array} & \\ & 25 \% & 647 & 40 & \text { Brazil (74\%), USA(4,8\%),India (3,1\%) } \\ \text { Video 1 } & 43 \% & 171 & 27 & \text { Brazil(48\%), USA(16\%), UK }(7,2 \%) \\ \text { Video 2 } & & & & \end{array}$




\begin{tabular}{|c|c|c|c|c|}
\hline Video 3 & $45 \%$ & 151 & 22 & $\begin{array}{l}\text { USA(38\%),Brazil( } 37 \%), \\
(7,6 \%)\end{array}$ \\
\hline Video 4 & $59 \%$ & 57 & 15 & $\begin{array}{l}\operatorname{Brazil}(62 \%), \mathrm{USA}(9,3 \%) \\
(5,9 \%)\end{array}$ \\
\hline Video 5 & $37 \%$ & 153 & 36 & $\operatorname{Brazil}(46 \%), \mathrm{USA}(19 \%), \mathrm{UK}(6,8 \%)$ \\
\hline Video 6 & $48 \%$ & 41 & 12 & $\operatorname{Brazil}(65 \%), \mathrm{USA}(7,6 \%), \operatorname{Romania}(7,2 \%)$ \\
\hline Video 7 & $31 \%$ & 77 & 18 & $\operatorname{Brazil}(51 \%)$, Canada(9\%),USA $(6,7 \%)$ \\
\hline Video 8 & $42 \%$ & 63 & 21 & Brazil (33\%),USA (26\%),UK $(4,9 \%)$ \\
\hline Video 9 & $33 \%$ & 78 & 23 & Brazil (41\%),USA(19\%),India $(8,7 \%)$ \\
\hline Video 10 & $29 \%$ & 73 & 19 & $\operatorname{Brazil}(48 \%), \mathrm{USA}(12 \%), \operatorname{Germany}(6,3 \%)$ \\
\hline Video 11 & $32 \%$ & 177 & 35 & $\mathrm{USA}(27 \%), \operatorname{Brazil}(20 \%), \mathrm{UK}(10 \%)$ \\
\hline Video 12 & $34 \%$ & 66 & 20 & $\operatorname{Brazil}(36 \%), \mathrm{USA}(13 \%)$, India $(10 \%)$ \\
\hline Video 13 & $44 \%$ & 63 & 17 & $\operatorname{Brazil}(51 \%), \mathrm{USA}(18 \%), \mathrm{UK}(7,7 \%)$ \\
\hline Video 14 & $46 \%$ & 316 & 45 & $\begin{array}{l}\text { USA(22\%),Brazil(12\%),New } \\
\text { Zealand(6,7\%) }\end{array}$ \\
\hline Video 15 & $34 \%$ & 60 & 19 & $\operatorname{Brazil}(54 \%), \mathrm{UK}(7,5 \%), \operatorname{USA}(7,5 \%)$ \\
\hline Video 16 & $31 \%$ & 186 & 30 & USA(53\%),Germany(18\%),Brazil( $15 \%)$ \\
\hline Video 17 & $34 \%$ & 233 & 29 & USA(32\%),Germany(19\%),India $(9,2 \%)$ \\
\hline Video 18 & $27 \%$ & 92 & 15 & $\begin{array}{l}\text { Brazil(72\%),Venezuela }(8 \%) \text {, } \\
\text { Germany }(4,9 \%)\end{array}$ \\
\hline
\end{tabular}

Table 4 presents data collected from Google Analytics reports related to the countries were the videos were watched. 
Table 4

\section{Countries}

\begin{tabular}{|c|c|c|c|c|}
\hline \multicolumn{3}{|c|}{ Countries } & \multirow[b]{2}{*}{ Oman } & \multirow[b]{2}{*}{ Spain } \\
\hline Arabic Emirates & Denmark & Israel & & \\
\hline Argelia & Egypt & Italy & Papua-New Guinea & Sri Lanka \\
\hline Argentine & Equator & Ivory Coast & Pakistan & Sudan \\
\hline Australia & Ethiopia & Jamaica & Peru & Sweden \\
\hline Austria & Finland & Japan & Philippines & Switzerland \\
\hline Barbados & France & Jordan & Poland & Taiwan \\
\hline Belgium & Georgia & Kenya & Portugal & Tanzania \\
\hline Bosnia & Germany & Luxemburg & Romania & Thailand \\
\hline Botswana & Ghana & Malaysia & Russia & $\begin{array}{l}\text { Trinidad and } \\
\text { Tobago }\end{array}$ \\
\hline Brazil & Greece & Maldives & Saudi Arabia & Turks and Caicos \\
\hline Bulgaria & Hong Kong & Mauricio Island & Seychelles & Uganda \\
\hline Cambodia & Hungary & Mexico & Singapore & Ukraine \\
\hline Canada & India & Netherlands & Slovakia & United Kingdom \\
\hline Czech & Indonesia & New Zealand & Slovene & Uruguay \\
\hline Chile & Iran & Niger & South Africa & USA \\
\hline Colombia & Ireland & Norway & South Korea & Venezuela \\
\hline
\end{tabular}

Table 5 presents the data collected from Google Analytics reports related to the sources of traffic. External traffic means that sources of traffic that were external to the Youtube environment. This traffic was generated by links from websites and by the use of search engines. Internal traffic is traffic generated within the Youtube environment. The internal traffic appears in table 5 in three different forms: Internal-Youtube research, InternalSuggestions from Youtube and Internal-Youtube Channel. 
Internal-Youtube research refers to the traffic generated by by internet users doing research directly within the Youtube environment. Internal-Suggestions from Youtube refers to the traffic generated by users who followed the suggestions automatically generated by Youtube's algorithm. Internal-Youtube Channel means the traffic generated when the users watched Youtube's channels.

The 'Other' category encompasses sources of traffic such as that originating from sharing videos on social networks and from embedding videos on websites, and other unidentified sources of traffic.

Table 5

\section{Origins of Traffic}

Video Origins of traffic

Video 1 External traffic (69\%), Internal-Youtube Channel (31\%)

Video 2 External traffic (48\%), Internal-Suggestions from Youtube (16\%) Other(36\%)

Video 3 External traffic (46\%), Internal-Youtube research (33\%), Other (21\%)

Video 4 External traffic (39\%), Internal-Suggestions from Youtube (24\%) Others (37\%)

Video 5 External traffic (43\%), Internal-Youtube research (22\%), Other(35\%)

Video 6 External traffic (73\%), Other(27\%)

Video 7 External traffic (26\%), Internal-Youtube research (19\%), Internal-Suggestions from Youtube (18\%), Other(37\%)

Video $8 \quad$ External traffic (48\%), Internal-Youtube research (22\%), Other(30\%)

Video 9 External traffic (44\%), Internal-Youtube research (22\%), Other(34\%)

Video 10 External traffic (42\%), Internal-Youtube research (23\%), Other(35\%)

Video 11 Internal-Youtube research (60\%), External traffic (28\%), Other(12\%)

Video 12 External traffic (34\%), Internal-Youtube research (22\%), Internal-Suggestions from Youtube (15\%), Other(29\%)

Video 13 External traffic (36\%), Other unknow websites (21\%), Other(43\%)

Video 14 External traffic (34\%), Internal-Youtube research (34\%), Other(32\%)

Video $15 \quad$ External traffic (47\%), Other(53\%) 

A Case Study

\author{
Video 16 External traffic (56\%), Internal-Youtube research (27\%), Other(17\%) \\ Video 17 External traffic (53\%), Internal-Youtube research (16\%), Other(31\%) \\ Video 18 External (34\%), Others (65\%)
}

\title{
Discussion
}

Analyzing the data presented, we can say that from October of 2012 to March of 2017, the 18 videos were watched 2,704 times (table 3 , sum of elements of the second column), in 80 countries (table 4). On average, each video was watched 150 times. The video watched in the greatest number of countries (45) was video 14; the least-watched video (video 6) was watched in 12 countries (table 3, fourth column). Brazil and the United States were the countries where the videos were most watched (table 3 , fifth column).

Why was Brazil the country where the majority of views originated?

We assume that it was due to the professor's actions to advertise the course to his students. During this period of five years the professor taught 18 system dynamics-related courses in Brazilian universities, encouraging approximately 360 students to watch the videos (table 1). In addition, the professor put links to the System Dynamics Self-Study Course on his websites and on his Youtube channel (table 2).

What were the impacts of the professor's actions advertising the course?

We may infer that those actions led to the increase in the number of visits to the professor's Youtube channel and to the increase in the number of visits to the course website, leading to the increase in the number of videos watched. In addition, we may say that the number of direct links created by the professor to the course webpage increased its visibility to the search engines, leading to more viewing (Figure 3, feedback loop 'Professor's efforts to promote the course').

This led us to our first finding:

The professor's actions to promote the course enabled direct access on the part of the students; it also led to wider viewership as a result of being picked up by search engines that made the videos available to a wider audience.

But why were people from all over the world watching the video? 


\section{Amaral \& Hess}

Business dynamics is taught as part of many system dynamics courses around the world (Forrester, 2007). Therefore, it is reasonable to suppose that there are many people interested in finding videos, in English, with information about this subject.

Table 5 shows that the main origin of traffic is external traffic (traffic generated by links from websites and by the use of search engines) in almost all videos. Table 5 also suggests that the second of source of traffic is Youtube itself. Once the professor put the videos on his Youtube channel, the Youtube algorithm helped to advertise them to Youtube users. When one user viewed one video of the course, the algorithm suggests others by the same author. (Figure 3, feedback loop named 'Youtube' recommendation').

This led us to our second finding:

Once the videos were on Youtube, Youtube and search engines algorithms stimulated increased viewership.

In addition, table 5 suggests that the Internet users shared the videos on social networks and by embedding the videos in their own websites. Thus, we assume that when users liked a video, they wanted to make it available to others. (Figure 3, feedback loops 'Embedding videos in websites' and 'Video-sharing in social network').

This led us to our third finding:

Internet users' actions such as sharing videos on their social networks and embedding the videos into their websites also increased the number of views.

Figure 3 summarizes the discussion.

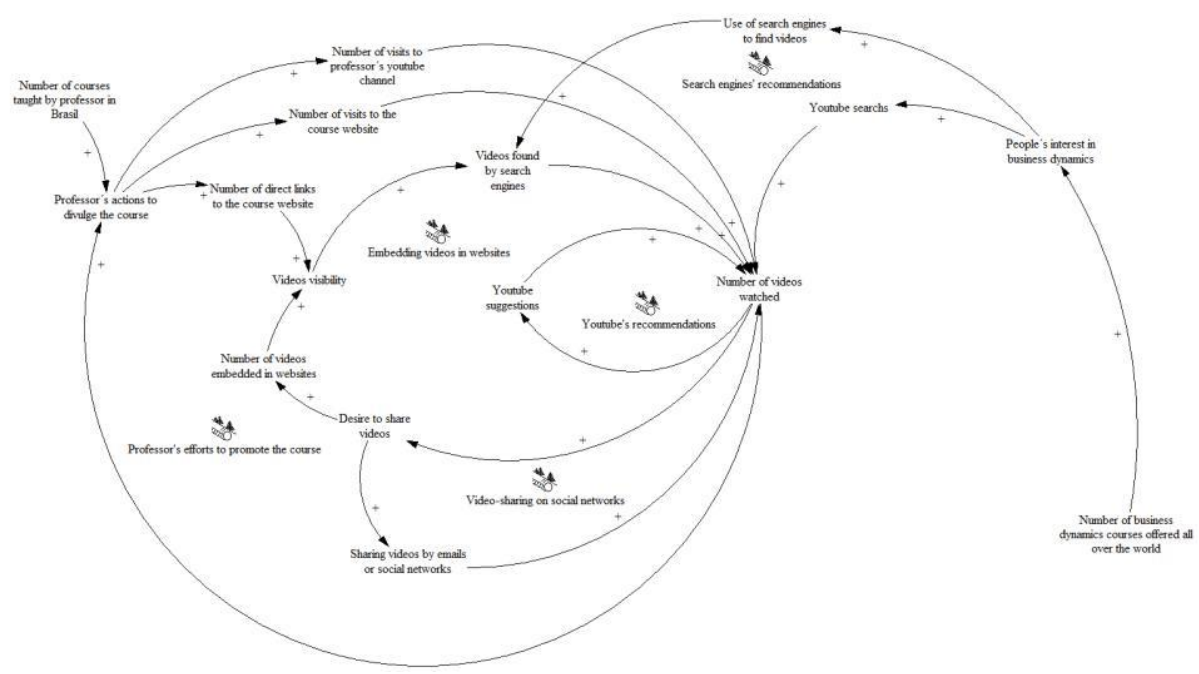


We thus conclude that the number viewings is result of the actions of the professor to promote the video, the actions of the search engines and Youtube algorithms, and the actions of those internet users who shared the videos with their friends.

The three dynamics are intertwined: once the videos were created and made available on Youtube, the videos took on a life of its own.

\section{Final remarks}

This case study focuses on the dynamics that unfolded as a result of the actions of a single professor creating a self-study course. However, we guess that the dynamics studied are present in broader contexts.

We assume that the video-courses that are part of OpenCourseware initiatives have similar dynamics: the main difference may be the order of magnitude. If courses have videos and the videos are on Youtube, they can become subject to similar reinforcing dynamics induced by Youtube algorithms and also to the video-sharing dynamics induced by Internet users.

Finally, it is interesting to notice that videos that were created with the purpose of supporting a group of 30 students is now is helping many more students all over the world.

\section{References}

Abelson, H. (2008). The creation of OpenCourseWare at MIT. Journal of Science Education and Technology, 17(2), 164-174.

Baluja, S., Seth, R., Sivakumar, D., Jing, Y., Yagnik, J., Kumar, S., Aly, M. (2008).

Video suggestion and discovery for youtube: taking random walks through the view graph. Proceedings of the 17th international conference on World Wide Web.

Brecht, H. D. (2012). Learning from online video lectures. Journal of Information Technology Education, 11, 227-250.

Burgess, J., \& Green, J. (2013). YouTube: Online video and participatory culture: John Wiley \& Sons.

Caswell, T., Henson, S., Jensen, M., \& Wiley, D. (2008). Open content and open 


\section{Amaral \& Hess}

educational resources: Enabling universal education. The International Review of Research in Open and Distributed Learning, 9(1).

Davidson, J., Liebald, B., Liu, J., Nandy, P., Van Vleet, T., Gargi, U., . . Livingston, B. (2010). The YouTube video recommendation system. Proceedings of the fourth ACM conference on Recommender systems.

Forrester, J. W. (2007). System dynamics — the next fifty years. System Dynamics Review, 23(2- 3), 359-370.

Lerman, S., \& Potts, J. P. (2006). Unlocking knowledge, empowering minds: MIT's OpenCourseWare project. IEEE signal processing magazine, 23(5), 11-15.

Noer, M. (2012). One man, one computer, 10 million students: How Khan Academy is reinventing education. Retrieved 10 April, 2017 from http://www. forbes. $\mathrm{com} / \mathrm{sites} / \mathrm{mich}$ aelnoer/2012/11/02/one-man-one-computer-10-million-studentshow-khan-academy-is-reinventing-education.

Rotman, D., \& Preece, J. (2010). The'WeTube'in YouTube-creating an online community through video sharing. International Journal of Web Based Communities, 6(3), 317-333

Simpson, N. (2006). Asynchronous access to conventional course delivery: a pilot project. British Journal of Educational Technology, 37(4), 527-537.

Thompson, C. (2011). How Khan Academy is changing the rules of education. Wired Magazine, 126, 1-5. 